\title{
THE WOUND HORMONES OF PLANTS
}

\section{TRAUMATIN, THE ACTIVE PRINCIPLE OF THE BEAN TEST}

\author{
By JAMES ENGLISH, JR., AND JAMES BONNER
}

(From the Gates and Crellin Laboratories of Chemistry and the William G. Kerckhoff Laboratories of the Biological Sciences, California Institute of Technology, Pasadena)

(Received for publication, June 22, 1937)

It has been shown by Wiesner (1) and Haberlandt (2) that when plant cells are injured substances are formed or liberated which are capable of causing other uninjured cells to divide. Such substances have been called "wound hormones" and the wound hormone problem has been the subject of numerous investigations $(3-5)$.

It is evident that this subject is of some importance from both theoretical and practical points of view. In the wound hormone we have a substance capable of bringing about renewed growth activity in mature cells-a type of growth analogous to that found in tumors and other abnormal growths. The rôle of the hormone in wound healing, parthenogenesis, callus formation, and other phenomena has been discussed by Haberlandt (2) and it has also been shown that the hormone is of great importance in the culture of plant tissues in vitro (6).

An attempt has been made in the present investigation to work out a specific test for wound hormone activity, and to use this test in the purification of the active principle of plant tissue extracts. In this way we have isolated a substance, possessing high wound hormone activity, for which we propose the name "traumatin." This name seems particularly appropriate in view of the historical background of the subject.

The test for traumatin activity was developed from the "bean test" of Wehnelt (3). This investigator as well as others used the actual frequency of cell division as a measure of wound hormone activity in this test. In the present investigation we have used

THE JOURNAL OF BIOLOGICAL CHEMISTRY, vOL. 121, No. 2 
the total amount of new growth, since this, in contrast with mitotic frequency, may be readily and accurately measured.

A detailed description of the "bean test" may be found elsewhere (7). Briefly, it may be said that the intact parenchymatous cells lining the string-bean pod respond to the application of traumatin solution with renewed cell division and cell elongation. If a drop of traumatin solution is placed within the seed chamber, an intumescence arises under the point of application. The height of this intumescence (under standard conditions (7)) has been used as one measure of activity. As a second measure of activity has been used the lowest concentration of traumatin which causes a typical wound hormone response. The reasons for the discrepancy between the comparative results obtained by these two independent measures of activity are not yet clear.

Traumatin, the active principle of the bean test, is widely distributed in plant tissues (7) but has not as yet been found in any animal material. The richest source of those so far investigated has been the bean pods themselves.

Traumatin is heat-stable and fresh beans may be dried in air (up to $100^{\circ}$ ) prior to extraction, without detectable loss of the active principle. It has been shown (8) that there is nothing to be gained by grinding the pods (thus "wounding" the cells severely) before drying.

In the procedure described we have used absolute alcohol extraction as the first step, since this avoids the introduction into the extract of large amounts of water-soluble impurities present in the pods.

\section{Procedure}

I. Extraction of Bean Pods-20 pounds of Kentucky Wonder bean pods were dried in an oven at $60-70^{\circ}$, ground, and placed in a modified Soxhlet extractor (8). The dried powder, which weighed $1050 \mathrm{gm}$., was extracted continuously with $3500 \mathrm{cc}$. of absolute ethanol for 20 hours, at the end of which time the extract returning to the boiling flask was pale yellow in color. The alcohol was evaporated under diminished pressure in an atmosphere of nitrogen at $50^{\circ}$ and the residual dark brown syrup extracted with three $100 \mathrm{cc}$. portions of warm water. The water extracts were combined and freed from oily material by filtering and 
centrifuging. Yield, $92 \mathrm{gm}$; ; relative activity 1.0 (based on height of new growth); dilution activity 1:400; diffusion molecular weight 440 .

II. Adsorption on Charcoal-To the above solution at room temperature were added $100 \mathrm{gm}$. of decolorizing charcoal (norit) and the mixture was stirred mechanically in an inert atmosphere for 1 hour. The charcoal was then filtered off and treated with five successive $150 \mathrm{cc}$. portions of pyridine. Each portion was allowed to stand with the charcoal with occasional shaking for 1 hour. The pyridine eluates were combined and evaporated at $50-60^{\circ}$ in nitrogen. (a) Filtrate, 40 gm., relative activity 0.0 ; (b) eluate, $52 \mathrm{gm}$., relative activity 1.5 ; dilution activity $1: 1600$; diffusion molecular weight 442 .

III. Ether Precipitation-Fraction II, $b$ was dissolved in 200 ce. of dry pyridine and to the resulting solution were added $200 \mathrm{cc}$. of ether. The oily precipitate was centrifuged and the filtrate evaporated as before at $50^{\circ}$ as far as possible. (a) Precipitate, $22 \mathrm{gm}$., relative activity 0.0 ; (b) filtrate, $30 \mathrm{gm}$., relative activity 1.4; dilution activity 1:4500; diffusion molecular weight 442 .

IV. Ethyl Acetate Extraction-The filtrate from the previous step was repeatedly extracted at room temperature with technical ethyl acetate in $150 \mathrm{cc}$. portions until the extracts became noticeably lighter in color; this required about $1000 \mathrm{cc}$. of solvent. The extracts were combined and evaporated as before at $50^{\circ}$. (a) Insoluble, $17 \mathrm{gm}$., relative activity 0.3 ; (b) soluble, $12 \mathrm{gm}$., relative activity 2.0 ; dilution activity $1: 12,800$; diffusion molecular weight 229.

V. Conversion to Barium Salts-Fraction IV, $b$ was dissolved in the smallest possible amount of cold water and treated with a saturated solution of barium hydroxide until distinctly alkaline. Carbon dioxide was then passed into the solution to remove excess barium hydroxide and the precipitate centrifuged and washed with water. The solution was then evaporated to dryness in vacuo and the residuc extracted with several portions of absolute ethanol. The alcohol-insoluble barium salts were then dissolved in water and the barium removed from the solution with sulfuric acid. The free acid obtained upon evaporation of the filtered solution was a dark brown, amorphous, hygroscopic material. (a) Alcohol extract, 3.9 gm., relative activity 1.6; (b) fraction 
(a) freed of $\mathrm{Ba}$ by $\mathrm{H}_{2} \mathrm{SO}_{4}, 1.6$; (c) free acid, $6.4 \mathrm{gm}$., relative activity 6.3 ; dilution activity $1: 36,000$; diffusion molecular weight 232.

VI. Mercuric Acetate Precipitation-A concentrated water solution of the active fraction from the previous step was treated with an excess of 20 per cent mercuric acetate solution and the resulting brown precipitate centrifuged off. The filtrate was saturated with hydrogen sulfide, filtered, and evaporated. The precipitate was suspended in water and allowed to stand under pressure of hydrogen sulfide overnight; this was repeated until no more color appeared in the filtered solution. After evaporation there remained an acidic product similar in appearance to Fraction $\mathrm{V}, c$ but somewhat lighter in color. (a) Filtrate, $3.0 \mathrm{gm}$., relative activity 2.8 ; (b) precipitate, 1.62 gm., relative activity 10.8; dilution activity 1:100,000; diffusion molecular weight 232 .

VII. Acetone Extraction-The highly active fraction from Fraction VI, $b$ was dissolved in dry acetone and the insoluble portion centrifuged. The acetone was then-removed in vacuo. (a) Acetone-insoluble, $0.216 \mathrm{gm}$., relative activity 10.8 ; $(b)$ acetonesoluble, $1.406 \mathrm{gm}$., relative activity 13.8 ; dilution activity $1: 100,000$; diffusion molecular weight 237.

Properties of the Free Acid-Since this has so far resisted all attempts to crystallize it or increase its activity by further precipitations, some of its properties are reported at this point.

The product is a yellow-brown, hygroscopic, amorphous solid, readily soluble in water, ethanol, acetone, and pyridine, insoluble or only slightly soluble in organic solvents such as benzene, ether, chloroform, or dry ethyl acetate. The active principle is fairly stable to the action of acids and alkalis, $5 \mathrm{~N}$ sodium hydroxide or $3 \mathrm{~N}$ hydrochloric acid having little effect on the activity at $100^{\circ}$, though $6 \mathrm{~N}$ hydrochloric acid under the same conditions decreases the activity very markedly. A hot solution of hydrogen peroxide ( 3 per cent) largely inactivates the substance, but the activity is quite unaffected by dilute nitrous acid, even on the steam bath. Phosphotungstic acid gives an amorphous precipitate and a small amount of an oily picrate can be obtained from aqueous solution. The substance is acidic in character, giving an equivalent weight of 214 by titration. The barium salt prepared from cold barium hydroxide solution or barium carbonate contains 
23.6 per cent barium, corresponding to an equivalent weight of 223. However, by heating the free acid with either acid or alkali, especially the latter, the barium content of the salt (prepared as above) is increasd to a value which seems to vary with the time of heating. The following analysis was obtained for Fraction VII, $b{ }^{1}$

C $51.58,51.34,51.84, \mathrm{H} 6.47,6.38,6.49, \mathrm{~N} 6.46,6.35$

The nitrogen content indicates an equivalent weight of 216 , and diffusion molecular weights varied from 225 to 237 .

VIII. Preparation of the Methyl Ester-In view of the difficulty of purifying the acid further it was decided to proceed through the ester. The usual method of esterification with alcohol and acid gave very poor yields and the following procedure was adopted.

A 5 per cent solution of the free acid in absolute ethanol was treated with a dry ether solution of diazomethane containing 5 times the theoretical amount (assuming one free carboxyl group in the molecule). The resulting solution, which was about 50 per cent ether and contained a small amount of fine precipitate, was allowed to stand, with occasional shaking, at $0^{\circ}$ for 1 hour and then at room temperature for another hour; at the end of this time the evolution of gas had ceased. The solvent was removed as usual and the residue treated with cold water and extracted with chloroform. After removal of the chloroform under diminished pressure the product was extracted with ether, with the addition of a small amount of water after the first few extractions, until no more color appeared in the ether layer. The dark yellow oil obtained by evaporating off the ether was transferred to a microdistilling bulb similar to that used by Kögl and Tönnis (9) and distilled under a high vacuum.

At $130-145^{\circ}$ and a pressure which varied in different runs from 0.2 to $0.007 \mathrm{~mm}$. a considerable quantity of light yellow oil appeared in the receiver; the main fraction distilled between 165 $185^{\circ}$ at $0.007 \mathrm{~mm}$. without apparent decomposition. The purified ester thus obtained was a very viscous yellow oil which became somewhat lighter in color on repeated distillation, but has not yet been obtained colorless or in the crystalline state.

${ }^{1}$ All combustions, Dumas nitrogen, and methoxyl determinations were carried out by Dr. Carl Tiedcke. 


\begin{tabular}{|c|c|c|}
\hline Fraction & $\begin{array}{c}\text { Yield, per } \\
\text { cent of } \\
\text { starting } \\
\text { material }\end{array}$ & $\begin{array}{l}\text { Relative } \\
\text { activity }\end{array}$ \\
\hline (a) Water-soluble & $\ldots 25$ & 13.1 \\
\hline (b) Ether-insoluble. & 30 & 2.3 \\
\hline (c) Ether-soluble. & 45 & \\
\hline$(c-1) 130-145^{\circ}$ & 8 & 1.6 \\
\hline (c-2) $165-185^{\circ}$. & 15 & 14.4 \\
\hline
\end{tabular}

Fractions (b), (c-1), and (c-2) being insoluble in water were hydrolyzed as described below for testing.

The loss of material on redistillation of fraction $(c-2)$ varied from 10 to 30 per cent, depending apparently on the amount of superheating. Temperatures were measured in the heating bath. In no case were more than $150 \mathrm{mg}$. distilled at one time and usually much less than this; hence there has not yet been enough material at hand for a satisfactory fractionation in the usual manner. Inasmuch as the same analytical results have been obtained from the products of three different extractions, it is perhaps not unreasonable to suppose that the ester distillate is at least approaching a state of purity and accordingly the analytical results are here reported. The ester was distilled at least twice and dried in vacuo at $76^{\circ}$ for analysis.

\begin{tabular}{lcc}
\multicolumn{1}{c}{ Found } & Average & ${ }^{\text {Calculated for }}$ \\
$\mathrm{C}_{11} \mathrm{H}_{17} \mathrm{O}_{4} \mathrm{~N}$
\end{tabular}

A determination, according to the method of Barger, in alcohol gave 224 for the molecular weight, the nitrogen content corresponds to 229, and the methoxyl to 230 . From this it may be seen that the diffusion molecular weights carried out on the free acid are somewhat high, but this is not surprising, considering the experimental errors of this method.

Properties of the Ester Distillate-This product is a very viscous yellow oil that does not crystallize on cooling, and is insoluble or only slightly soluble in water and petroleum ether, and soluble in alcohol, chloroform, ether, benzene, and acetone. It decolorizes permanganate in the cold and preliminary catalytic hydrogenation experiments seem to indicate the presence of two double bonds; this, however, requires confirmation. The sub- 
stance is not strongly basic and has so far yielded no crystalline derivative.

Hydrolysis of the Ester Distillate--The product described above was dissolved in a small amount of ethanol and an equal volume of saturated barium hydroxide solution was added. The solution was then heated under a reflux for 3 to 5 hours and the excess barium precipitated with carbon dioxide. Upon again evaporating the filtered solution to dryness at $50^{\circ}$ in the usual manner, there remained an alcohol-insoluble barium salt. This was a yellow amorphous solid, soluble in water and insoluble in organic solvents. Sometimes it was necessary to repeat the hydrolysis in order to obtain a completely water-soluble product.

$$
\begin{array}{lll}
\mathrm{C}_{9} \mathrm{H}_{11} \mathrm{O}_{4} \mathrm{NBa} . & \text { Calculated. } & \mathrm{Ba} 41.0 \\
\left(\mathrm{C}_{10} \mathrm{H}_{14} \mathrm{O}_{4} \mathrm{~N}\right)_{2} \mathrm{Ba} . & \text { " } & \text { " } 31.7 \\
& \text { Found. } & \text { " } 40.5,40.8
\end{array}
$$

This barium salt was taken up in the minimum amount of water and the barium quantitatively removed from the solution with sulfuric acid. Upon evaporation there remained an amorphous hygroscopic solid, very similar in appearance and precipitation reactions to the free acid of Fraction VII, $b$. The average yield of material thus hydrolyzed was 60 per cent of theory. The activity has been found to be very nearly the same as that of Fraction VII, $b$.

\section{DISCUSSION}

It is evident from the analytical data in the preceding part that the substance under consideration in this case is markedly different from that isolated by Umrath and Soltys (10). These authors described their substance as giving an equivalent weight of 193 by titration and containing 2.5 per cent nitrogen; they also prepared an acetyl derivative which gave 45.4 per cent acetyl. An attempt to acetylate the ester distillate with acetic anhydride in pyridine gave a compound containing 6.15 per cent nitrogen, indicating that no acetyl groups had been introduced under the conditions used by Soltys and Umrath (11).

The diffusion molecular weights were determined by carrying out diffusion experiments according to the method first developed by Went (12) and testing the agar blocks directly in the bean test. The curves of concentration against height of growth of traumatin 
in agar are identical with those obtained by testing drops of solutions. This method of determination of molecular weight is theoretically independent of the purity of the sample, depending as it does only on the physiological test for the result. The apparent change in this value observed at step (IV) is therefore rather difficult to understand, particularly since the same change took place at step (II) in another extraction. The correct explanation of this phenomenon cannot as yet be given.

With regard to the possibility of the presence of several growth factors which might influence the test, it should be noted that at each step combination tests have been carried out with the active and inactive fractions, without, however, finding any evidence that a second essential substance, itself inactive or only slightly active, had been separated from the concentrate at any step. It can be seen from the preceding section that no significant amount of active material has been discarded, with the possible exception of Fraction VIII, $a$, and upon treating this with a second portion of diazomethane its activity was greatly reduced with the production of more of fractions $(b)$ and $(c)$.

With regard to the type of nitrogen linkage present in the molecule, it can only be said with reasonable assurance that it is not a primary amino group, since aqueous nitrous acid, even when heated, is without effect on the activity.

Although it is quite possible that the ester distillate is not perfectly pure, we feel safe in deducing from the nitrogen and methoxyl content that it is a monomethyl ester.

The hydrolyzed ester gave the same diffusion molecular weight as did the free acid starting material and hence has not undergone any drastic cleavage during hydrolysis. The barium salt of this product, however, contained 40.7 per cent barium, corresponding to an equivalent weight of 102 . In other words, the substance, originally monobasic (from the methoxyl content) now appears to be a dibasic acid, and it is reasonable to assume that in the original acid there existed one free carboxyl group and one in the form of a lactone, inner amide, or betaine type of structure. It is also worthy of note that the barium content of this salt corresponds more closely to the loss of two $\mathrm{CH}_{2}$ groups from the ester molecule than to the lower value which would result from the simultaneous hydrolysis of a lactone and a methyl ester grouping. 
It should perhaps be emphasized that the present suggestions are to be regarded as tentative and subject to revision; and that the empirical formula $\mathrm{C}_{10} \mathrm{H}_{15} \mathrm{O}_{4} \mathrm{~N}$ may be somewhat in error. Preparations are being made to work up a large quantity of material and establish beyond reasonable doubt the purity of the final product.

The authors wish to express their gratitude to Professor F. W. Went for the encouragement and advice tendered by him during this research.

\section{SUMMARY}

A quantitative biological test has been used in a study of a wound hormone of plants.

By this test, a substance which is believed to be the nearly pure hormone has been isolated from bean pods.

This hormone was found to be an amorphous, water-soluble, acidic compound, active in the test to a dilution of $1: 100,000$. Preliminary analyses indicate an empirical formula $\mathrm{C}_{11} \mathrm{H}_{17} \mathrm{O}_{4} \mathrm{~N}$ for the monomethyl ester.

The authors have suggested the name "traumatin" for this wound hormone.

\section{BIBLIOGRAPHY}

1. Wiesner, J., Die Elementarstructur und das Wachstum der lebenden Substanz, Vienna, 102 (1892).

2. Haberlandt, G., Biol. Zentr., 42, 145 (1922); Beitr. allg. Bot., 2, 1 (1921).

3. Wehnelt, B., Jahrb. wissensch. Bot., 66, 773 (1927).

4. Reiche, H., Z. Bot., 16, 241 (1924).

5. Wilhelm, J., Jahrb. wissensch. Bot., 72, 203 (1930).

6. Bonner, J., Proc. Nat. Acad. Sc., 22, 426 (1936).

7. Bonner, J., and English, J., Plant Physiol., in press.

8. Cameron, A. E., Ind. and Eng. Chem., Anal. Ed., 4, 392 (1932).

9. Kögl, F., and Tönnis, B., Z. physiol. Chem., 242, 67 (1936).

10. Umrath, K., and Soltys, A., Jahrb. wissensch. Bot., 84, 276 (1936).

11. Soltys, A., and Umrath, K., Biochem. Z., 284, 287 (1936).

12. Heyn, A., Proc. Acad. Sc. Amsterdam, 38, 3 (1935). 